\title{
Real-World Treatment Patterns, Outcomes, Resource Utilization and Costs in Treatment-Resistant Major Depressive Disorder: PATTERN, a Retrospective Cohort Study in Belgium
}

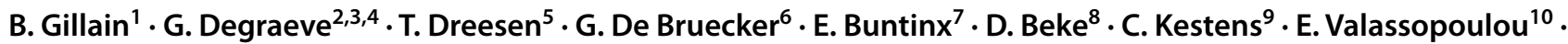

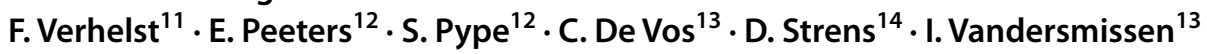

Accepted: 21 September 2021 / Published online: 15 November 2021

(c) The Author(s) 2021

\begin{abstract}
Objective Treatment-resistant depression (TRD), a subgroup of major depressive disorder (MDD) that does not adequately respond to treatment, has a substantial impact on the quality of life of patients and is associated with higher medical and mental health care costs. This study aimed to report real-world treatment patterns, outcomes, resource utilization, and costs in the management of TRD by psychiatrists in Belgium.

Methods We conducted a retrospective, non-interventional cohort study of patients $\geq 18$ years, with diagnosed MDD who are treatment-resistant, defined as not responding to two different antidepressant treatments in the current moderate to severe major depressive episode (MDE). Data obtained from medical records of patients included patient health state (MDE, response, remission, and recovery) and resource use (number of consultations and emergency room visits, non-drug and drug interventions, and hospitalizations).

Results One hundred and twenty-five patients were enrolled in nine sites, with an average observation period of 34 months. During the MDE, $89.7 \%$ of patients were treated with selective serotonin reuptake inhibitors, $63.2 \%$ with serotonin-norepinephrine reuptake inhibitors, and $60.8 \%$ with anti-psychotics. Twenty-four percent of patients did not respond to any treatment; $76 \%$ responded, of whom $61 \%$ experienced a relapse; $28 \%$ of patients reached recovery, of whom $31.4 \%$ experienced recurrence. The average yearly direct cost of a TRD patient is $€ 9012$, mainly driven by hospitalization in the MDE. The observed absenteeism relates to a high indirect cost, representing $70 \%$ of the total MDE cost.

Conclusion TRD is associated with a high unmet need and economic burden for patients and society, with highest costs in the MDE health state driven by absenteeism.
\end{abstract}

B. Gillain and G. Degraeve are co-first authorship.

I. Vandersmissen

ivander6@its.jnj.com

Extended author information available on the last page of the article

\section{Key Points for Decision Makers}

The first retrospective study on clinical management of treatment-resistant depression (TRD) patients in Belgian specialized care indicates the high unmet need in TRD, as only $28 \%$ of patients reached recovery during the observation period.

The direct and indirect economic burden of TRD is highest in the major depressive episode health state, with $70 \%$ of the total cost due to absenteeism.

Both findings underscore the urgent need for effective treatment strategies for the TRD patient population. 


\section{Introduction}

Major depressive disorder (MDD) is a common mental health disorder affecting more than 264 million people worldwide [1]. In high-income countries, the 12-month prevalence of MDD is 5.1\% [2]. Despite available therapies, 20-30\% of MDD patients do not adequately respond to treatment and can be considered treatment resistant [3-6]. European Medicines Agency (EMA) guidelines define treatment-resistant depression (TRD) when a patient treated with at least two different antidepressant agents (of the same or a different class) prescribed in adequate dosages for an adequate duration and with adequate affirmation of treatment adherence shows lack of clinically meaningful improvement [7].

During the study period there was no pharmaceutical treatment approved by the EMA for TRD and hence TRD patients were mainly treated with pharmacotherapy indicated for MDD. In the US, Symbyax (olanzapine and fluoxetine hydrochloride) is indicated for TRD and only recently the US Food and Drug Administration (FDA) and the EMA approved Spravato (esketamine), a new therapeutic option in TRD. Observational studies in depressed patients report lower remission rates and higher relapse rates for each additional treatment step [8]. TRD patients experience a high burden of disease, with only $20 \%$ probability of achieving remission and substantially lower quality-of-life scores than patients responding to treatment $[9,10]$. Compared with MDD, TRD is associated with seven times higher risk of suicide [11] and two times higher occurrence of comorbidities [12].

Characterized by a longer duration and a more severe course, TRD is associated with a higher number of emergency room (ER) visits and hospitalizations, and higher rates of disability and absenteeism, resulting in around two-fold higher direct and indirect costs compared with MDD [10, 13, 14]. In Belgium, depression is associated with an average yearly direct cost of $€ 6549$ [15] and is the main cause of long-term work disability, resulting in high indirect costs [16].

Data on the direct and indirect costs according to TRD-related health states in real-world clinical practice can further characterize the economic impact of TRD. In addition, data on the management of TRD in Belgium are limited. Therefore, the objective of this study was to assess real-world treatment patterns, outcomes, and health care resource utilization in the management of adult TRD patients treated by psychiatrists in Belgium. This study is the first to assess the associated direct and indirect costs, according to four predefined health states (major depressive episode, response, remission, and recovery), in realworld clinical practice.

\section{Methods}

\subsection{Study Design}

An observational retrospective patient chart review was performed in which the treating psychiatrists selected eligible TRD patients by reviewing retrospectively the medical records in the index window of June 1, 2014-April 1, 2017. Taking into account clinical and health-economic expert advice and feasibility assessment, the target sample size was set at 100-150 patients in 6-10 sites representative of the three different treatment settings in Belgium: private practice, general hospital, and psychiatric hospital, to allow the collection of a substantial and representative dataset.

Patients aged $\geq 18$ years were eligible upon initial diagnosis of MDD according to DSM-5, and subsequently fulfilling the TRD definition: MDD not responding to two different treatments with antidepressants (ADs) in the current moderate to severe depressive episode. One AD treatment corresponds to either AD monotherapy, with or without augmentation or $\mathrm{AD}$ combination therapy. Patients were eligible if the fulfillment of the TRD definition (not responding to two different treatments with ADs) occurred in the index window and if a follow-up period of at least 2 years was available. The observation period started when the third treatment line was initiated, following non-response to two prior treatments with antidepressants in the baseline period. Patients who refused participation and patients with insufficient data on resource use (lost to follow-up, unless the patient died) were excluded. Patients were treated according to routine clinical practice.

\subsection{Data Collection}

All living patients consented for participation and data were obtained from the patients' medical records. An electronic case record form (eCRF) per patient was completed by the physician. Patient confidentiality was ensured by the autogeneration of a unique patient identification number by the eCRF platform, which anonymized the data used in the analysis. At the start of the observation period, the following characteristics were collected: year of birth; gender; onset of baseline major depressive episode (MDE); pharmacological treatments and non-pharmacological therapies in the current episode; concomitant conditions; employment status.

During the observation period, patient health state and resource use were followed up and analyzed in monthly periods. Four health states were defined: MDE, response, remission, and recovery. MDE was the baseline health state at the start of the observation period and upon relapse (following response or remission) or recurrence (following recovery). Due to the retrospective nature of the study and 
the real-world setting, response, remission, and recovery were defined descriptively. Response was defined as a clear and clinically meaningful reduction in symptoms, along with some improvement in role functioning, but distress or impairment from the illness persisted; objectified by a Clinical Global Impression (CGI)-Improvement rating of 2 (much improved). Remission referred to normal or only minimal symptoms, objectified by overall CGI-Severity rating of 1 (normal). Recovery was defined as an uninterrupted remission for 6 months $[17,18]$.

The following resource use data was collected during the observation period per health state: number of visits to health care professional; number of psychotherapy sessions; number of ER visits; non-pharmacological therapy (type, number of sessions); and number of diagnostic tests performed. For AD therapy, the drug name, dose, start date, end date, and frequency were collected; for other drug therapies, drug name, start, and duration were collected. For (day) hospital stays, the type of setting, admission and discharge date, and reason for hospitalization were collected. Sick leave days and changes in employment status were also obtained from the medical records.

Data management and analysis was centralized. In case of questions with regard to interpreting records in medical charts or coding the data, data validation was discussed and resolved.

\subsection{Data Analysis}

Formal hypothesis testing was not performed and therefore sample size calculations were not undertaken.

Descriptive analyses of the demographic and clinical characteristics of patients were carried out. The study did not have the objective to assess the effect of (different types of) exposure on outcome (TRD-related health state), and controlling for confounding was thereby not applicable. The average time to reach response to treatment was calculated by means of the Kaplan Meier technique, using XLSTAT software. The program used Greenwood's method to estimate the variance of the Kaplan-Meier curves [19].

A subgroup analysis according to the treatment setting was conducted. For the subgroup analysis on the treatment and resource utilization of patients in the third line of treatment, treatment change to fourth line of treatment was defined as a switch in $\mathrm{AD}$, addition of $\mathrm{AD}$, or augmentation with mood stabilizer (MS), anti-psychotic (AP), or lithium. Reduction in therapy was not considered as a change.

Medical resources used were multiplied by the cost obtained from official INAMI listings in 2019 to calculate the cost from a national health insurance and patient perspective [20]. Since costs do not usually follow a normal distribution, a robust confidence interval of the mean was calculated by bootstrapping. Indirect absenteeism costs were based on the average number of calendar days 'not working' per month for patients in the active population, meaning patients on short-term sick leave, on long-term sick leave (indicated as disability), working part-time, working fulltime, or self-employed at baseline. Calendar days correspond to an average number of working hours lost per month taking into account on average $61.8 \%$ of calendar days are working days, with an average of 7.6 working hours per full-time working day and adjusting for the weighted percentage of working time in active TRD patients of $85.3 \%$, based on $64 \%$ full-time workers and $36 \%$ part-time (with, on average, $59.3 \%$ work time). Health state-specific indirect costs were calculated by applying the hourly labor cost in Belgium in 2018 of $€ 39.70$ per working hour lost [21], for the active population $(81.51 \%)$.

\section{Results}

\subsection{Baseline Characteristics}

In total, 125 patients were included in the study, from four sites in the Walloon region and five in Flanders. Seventy-five patients $(60.0 \%)$ were women. The average age at the start of the observation period was 48.4 years (standard deviation [SD] 13.8). For 36 (28.8\%) patients, the treatment setting was a private practice, for $58(46.4 \%)$ a general hospital, and for $31(24.8 \%)$ a psychiatric hospital. Three patients died (2.4\%), of whom one death was related to MDE (suicide). In $67.0 \%$ of patients, concomitant conditions were recorded. Alcoholism (20.0\%), sleep disorder (12.8\%), anxiety disorder $(12.0 \%)$, stress (10.4\%), hypertension (8.8\%), and diabetes mellitus $(8.8 \%)$ were the most common concomitant conditions.

At the start of the observation period, $81.5 \%$ of the 119 patients with reported employment status were active, with $23.5 \%$ working and $58.0 \%$ on sick leave/disability. The remaining $18.5 \%$ were retired, homemakers, students, or not seeking employment. Of those employed, $64.0 \%$ were working full time and $36.0 \%$ part time with, on average, 59.3\% work time. More details on the baseline characteristics can be found in Table 1.

\subsection{Pharmacological Treatment in Major Depressive Disorder (MDD)}

First-line treatment for baseline MDE, prior to the observation period, was AD monotherapy in $54.4 \%$ of patients and monotherapy + augmentation in $27.2 \%$ of patients. Selective serotonin reuptake inhibitors (SSRIs) were the most prescribed drug class in monotherapy (57.4\%) and APs were the most prescribed augmentation drugs 
Table 1 Baseline characteristics of patients included in the study $(N=125)$

\begin{tabular}{|c|c|}
\hline \multicolumn{2}{|l|}{ Characteristic } \\
\hline Age, mean (SD) & $48.4(13.8)$ \\
\hline Females, $n(\%)$ & $75(60.0)$ \\
\hline \multicolumn{2}{|l|}{ Geographical location of site, $\mathrm{n}(\%)$} \\
\hline Walloon region & $4(44)$ \\
\hline Flanders & $5(56)$ \\
\hline \multicolumn{2}{|l|}{ Treatment setting, $n(\%)$} \\
\hline Private practice & $36(28.8)$ \\
\hline General hospital & $58(46.4)$ \\
\hline Psychiatric hospital & $31(24.8)$ \\
\hline \multicolumn{2}{|l|}{ Concomitant conditions, $n(\%)^{\mathrm{a}}$} \\
\hline Alcoholism & $25(20.0)$ \\
\hline Sleep disorder & $16(12.8)$ \\
\hline Anxiety disorder & $15(12.0)$ \\
\hline Stress & $13(10.4)$ \\
\hline Hypertension & $11(8.8)$ \\
\hline Diabetes mellitus & $11(8.8)$ \\
\hline Drug addiction/substance abuse & $8(6.4)$ \\
\hline Psychotic disorder & $8(6.4)$ \\
\hline Personality disorder & $7(5.6)$ \\
\hline Obesity & $7(5.6)$ \\
\hline \multicolumn{2}{|l|}{ Employment status, $n(\%$ of $N=119)$} \\
\hline Active-working & $28(23.5)$ \\
\hline Active—on sick leave/disability & $69(58.0)$ \\
\hline Not active ${ }^{b}$ & $22(18.5)$ \\
\hline \multicolumn{2}{|c|}{ Job regimen, $n$ ( $\%$ of $N=97$ patients with employment) } \\
\hline Full time & $62(64.0)$ \\
\hline Part time & $35(36.0)$ \\
\hline
\end{tabular}

${ }^{a}$ Concomitant conditions reported in $<5 \%$ of the patients: emotional disorder, eating disorder(s), chronic fatigue syndrome, borderline, Parkinsonism, pervasive developmental disorder, chronic pulmonary disease, rheumatological disease, congestive heart failure, hernia, hypercholesterolemy, renal disease, any malignancy including leukemia and lymphoma, metastatic solid tumor, disruptive behavioral disorder, hyperthyroidism, schizophrenia, chronic pain, subdural bleed, lupus, gastric bypass, inflammation shoulder, tremor, Sjogren syndrome, amnesia, burns, neuropathy, autism, asthma

${ }^{\mathrm{b}}$ Retired, homemaker, student, or not seeking employment

(76.5\%). Second-line treatment for the baseline MDE was monotherapy with or without augmentation in $60.0 \%$ of patients, with SSRI as the most prescribed drug class. Prior to the start of the observation period, $7.2 \%$ of patients received electroconvulsive therapy and $79.2 \%$ of patients received psychotherapy (Table 2). Upon initial MDD diagnosis, patients were on average treated for 19.0 months during the first two AD treatments prior to meeting the TRD definition (start of the observation period), with a minimum of 2.1 months confirming adequate duration of treatment.

\subsection{Pharmacological Treatment in Treatment-Resistant Depression (TRD)}

The most commonly administered pharmacotherapy to TRD patients in the MDE health state were SSRIs (89.7\% of patients), serotonin-norepinephrine reuptake inhibitors (SNRIs, 63.2\%), tricyclic antidepressants (TCAs, 32.8\%), and other ADs (32.0\%). The majority of patients received augmentation therapy at least once during the observation period, mainly with AP (60.8\% of patients), MS (21.6\%) or lithium $(4.8 \%)$. Also, benzodiazepines (41.6\%), hypnotics (10.4\%), $\beta$-blockers (10.4\%), and thyroxine (6.4\%) were prescribed. Electroconvulsive therapy was performed in five patients in the MDE health state (4.0\%), with an average of 6.8 sessions (SD: 4.8 ).

As third-line treatment (first line in TRD), $34.4 \%$ of patients were on AD monotherapy, mainly with an SSRI or SNRI. In $27.2 \%$ of patients, augmentation therapy was used, mainly with AP; $14.4 \%$ of patients were treated with a combination of ADs and $20.0 \%$ with a combination of AD and augmentation therapy (Table 2). Following initiation of third-line therapy, $29.6 \%$ of patients persisted on their ADs throughout the study period, and $70.4 \%(n=88)$ underwent at least one treatment change. In fourth line (second line in TRD), patients were mainly treated with monotherapy with augmentation $(21.6 \%)$ and combination therapy with or without augmentation (both 37.5\%). The average duration of the observation period was 2 years and 10 months.

\subsection{Outcomes}

Over the total observation period, patients were on average 1 year and 7.3 months in the MDE health state (initial MDE + MDE upon relapse/recurrence). The average time in MDE was shorter in patients seen by a psychiatrist in a private practice (11.2 months) than for patients seeing a psychiatrist linked to a general hospital (1 year and 8.8 months) or psychiatric hospital (2 years and 2.1 months) (Table 3 ).

At the start of the observation period, the average baseline MDE duration was 1 year and 2.8 months (SD: 14.5 months). An average of 3.6 health states (SD: 2.4) were recorded per patient, with the number of patients and the average (SD) duration per health state shown in Table 3. Twenty-four percent of patients did not respond to currently available therapies and remained in the MDE health state. Ninety-five patients (76.0\%) showed improvement during the observation period: 95 patients reached response $(n=80$, $64.0 \%)$ and/or remission $(n=55,44.0 \%)$, among whom 35 patients $(28.0 \%)$ reached recovery. Of the 95 patients who reached response and/or remission, $61.1 \%$ relapsed during the observation period, with a subsequent average MDE health state duration of 8.9 months. Of the 35 patients that reached recovery, $31.4 \%$ experienced a recurrence during the 
Table 2 Pharmacological treatment prior to the observation period (MDD, first and second line) and during the observation period (TRD, third and fourth line)

\begin{tabular}{|c|c|c|c|c|}
\hline & \multicolumn{2}{|l|}{ MDD } & \multicolumn{2}{|l|}{ TRD } \\
\hline & $\begin{array}{l}\text { First-line AD } \\
(n=125), \%\end{array}$ & $\begin{array}{l}\text { Second-line AD } \\
(n=125), \%\end{array}$ & $\begin{array}{l}\text { Third-line AD } \\
(n=125), \%\end{array}$ & $\begin{array}{l}\text { Fourth-line } \\
\mathrm{AD}(n=88), \\
\%\end{array}$ \\
\hline Monotherapy & 54.4 & 35.2 & 34.4 & 2.3 \\
\hline SSRIs & 57.4 & 50.0 & 44.2 & 50.0 \\
\hline SNRIs & 17.6 & 29.5 & 41.9 & 0.0 \\
\hline TCAs & 4.4 & 15.9 & 9.3 & 50.0 \\
\hline Other AD & 20.6 & 4.5 & 4.7 & 0.0 \\
\hline Monotherapy + augmentation & 27.2 & 24.8 & 27.2 & 21.6 \\
\hline Monotherapy + AP & 76.5 & 67.7 & 61.8 & 78.9 \\
\hline Monotherapy + MS & 2.9 & 9.7 & 14.7 & 5.3 \\
\hline Monotherapy + LI & 8.8 & 0.0 & 0.0 & 0.0 \\
\hline Monotherapy + AP + MS & 2.9 & 9.7 & 20.6 & 15.8 \\
\hline Monotherapy + AP + LI & 5.9 & 9.7 & 2.9 & 0.0 \\
\hline Monotherapy + AP + MS + LI & 2.9 & 3.2 & 0.0 & 0.0 \\
\hline Combination therapy & 7.2 & 24.0 & 14.4 & 37.5 \\
\hline Combination therapy + augmentation & 11.2 & 16.0 & 20.0 & 37.5 \\
\hline Monotherapy AP & 0.0 & 0.0 & 1.6 & 1.1 \\
\hline Other & 0.0 & 0.0 & 2.4 & 0.0 \\
\hline
\end{tabular}

Details on drugs per drug category can be found in Supplementary Table 1 (see electronic supplementary material)

$A D$ antidepressants, $A P$ antipsychotics, $L I$ lithium, $M D D$ major depressive disorder, $M S$ mood stabilizer, SNRIs serotonin-norepinephrine reuptake inhibitors, SSRIs selective serotonin reuptake inhibitors, TCAs tricyclic antidepressants, $T R D$ treatment-resistant depression

Table 3 Number of patients and duration per health state during observation period

\begin{tabular}{|c|c|c|c|c|c|c|}
\hline Health states during observation period & Number of patients (\%) & $\begin{array}{l}\text { Average (SD) cumula- } \\
\text { tive duration in monthly } \\
\text { periods }\end{array}$ & Median & IQR & Min & $\operatorname{Max}$ \\
\hline MDE (initial health state + relapse/recurrence) & $125(100.0 \%)$ & $19.3(13.5)$ & 18.7 & 21.6 & 0.3 & 60.0 \\
\hline MDE in patients in private practice & $36(28.8 \%)$ & $11.2(12.3)$ & 6.4 & 13.2 & 0.4 & 37.8 \\
\hline MDE in patients in general hospital & $58(46.4 \%)$ & $20.8(12.3)$ & 20.1 & 14.8 & 0.3 & 60.0 \\
\hline MDE in patients in psychiatric hospital & $31(24.8 \%)$ & $26.1(12.4)$ & 24.8 & 23.0 & 6.1 & 49.2 \\
\hline MDE (initial period alone) & $125(100.0 \%)$ & $14.8(14.5)$ & 9.9 & 19.9 & 0.1 & 60.0 \\
\hline MDE (initial period alone in patients with relapse/recurrence) & $65(52.0 \%)$ & $7.2(6.1)$ & 4.7 & 11.0 & 0.1 & 23.5 \\
\hline Response & $80(64.0 \%)$ & $11.9(8.4)$ & 9.7 & 11.4 & 0.7 & 40.6 \\
\hline Remission & $55(44.0 \%)$ & $7.7(5.6)$ & 6.0 & 2.2 & 1.0 & 30.3 \\
\hline Recovery & $35(28.0 \%)$ & $12.7(5.0)$ & 13.6 & 8.2 & 2.7 & 21.6 \\
\hline $\begin{array}{l}\text { Relapse and/or recurrence (\% of patients with response/ } \\
\text { remission, } N=95 \text { ) }\end{array}$ & $65(68.4 \%)$ & $8.8(7.2)$ & 7.1 & 7.5 & 0.2 & 28.8 \\
\hline Relapse only (\% of patients with response/remission, $N=95$ ) & $58(61.1 \%)$ & $8.9(7.1)$ & 7.1 & 7.5 & 0.2 & 28.8 \\
\hline Recurrence only ( $\%$ of patients with recovery, $N=35$ ) & $11(31.4 \%)$ & $5.3(6.9)$ & 2.1 & 3.2 & 1.0 & 24.1 \\
\hline
\end{tabular}

$I Q R$ interquartile range, $M D E$ major depressive episode, $S D$ standard deviation

observation period, with a subsequent average MDE health state duration of 5.3 months. In Supplemental Fig. 1, the sequence of the reported health states is depicted (see Electronic Supplementary Material [ESM]).
For responders, the mean (median) time to response was 7.9 months (5.1 months), including patients in the remission health state who also met the response criterium. The mean time to remission was 11.5 months ( 8.3 months) and 
mean time to the first relapse following reaching response was 10.8 months (8.0 months).

\subsection{Medical Resource Utilization}

During the observation period, 39 patients $(31.2 \%)$ were hospitalized with 112 hospitalizations, corresponding to an average of 2.9 (SD: 2.2) hospitalizations per hospitalized patient, all occurring in the MDE health state. The average length of stay was 32 days in a general hospital and 68 days in a psychiatric hospital. The most frequently reported reasons for hospitalization were inability to function $(50.9 \%)$ and suicidal ideation or attempt (23.4\%). Furthermore, in the MDE health state, $9.6 \%$ of patients visited the day hospital with on average 30.6 day hospitalizations, and $16.8 \%$ of patients required an ER visit not followed by hospitalization.

The average (SD) yearly number of psychiatrist visits (including psychotherapy) per patient was 12.7 (30.5) in the MDE health state, 11.2 (11.4) in response, and 11.9 (10.4) in remission and recovery. In the MDE health state, lab tests, ECGs and EEGs were performed in $20.0 \%, 24.8 \%$, and $27.2 \%$ of patients, respectively (Supplementary Table 2, see ESM).
Fig. 1 Average direct cost per TRD patient: per year (a) and per month by health state (b). $M D E$ major depressive episode, TRD treatment-resistant depression. Details on the average direct cost per patient per month can be found in Supplementary Table 3 (ESM)

\section{a Average TRD patient cost per year}

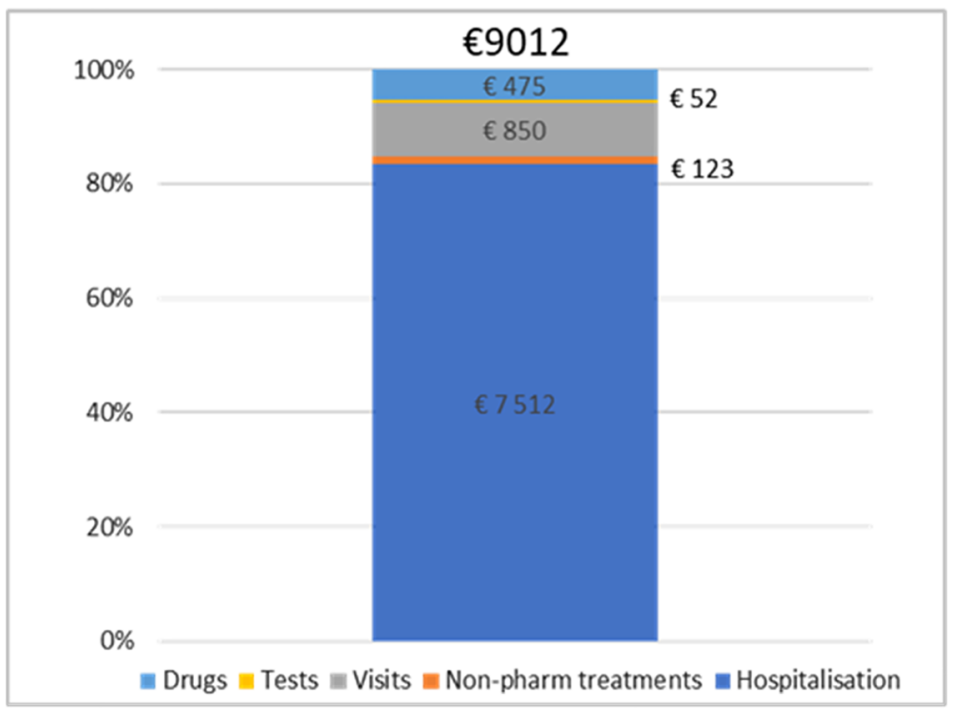

b Average monthly cost per patient per health state

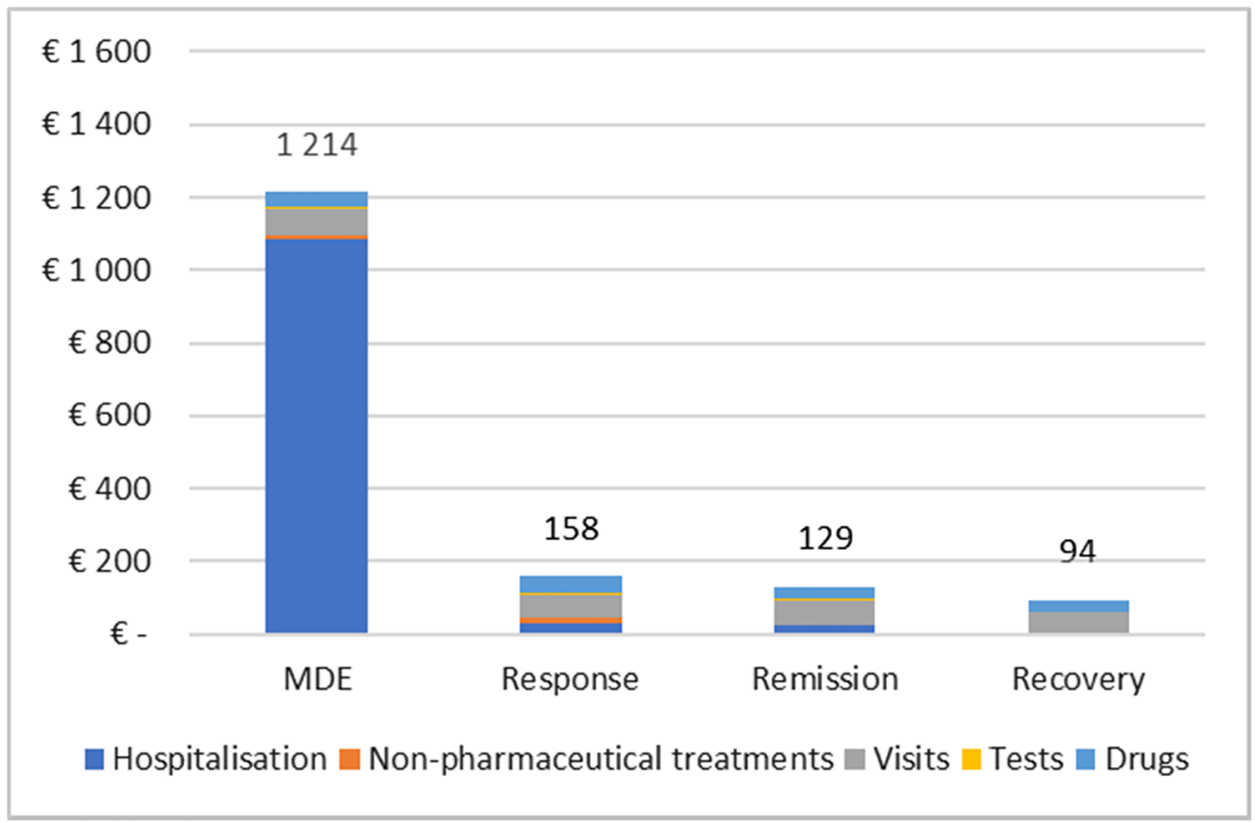

Abbreviations: $\mathrm{MDE}=$ major depressive episode; $\mathrm{TRD}=$ treatment-resistant depression 


\subsection{Absenteeism}

At the end of the observation period, $25.8 \%$ of patients were working, $49.2 \%$ were on sick leave/disability, and $25.0 \%$ were not working (retired, homemaker, student, or not seeking employment). The average (SD) number of calendar days 'not working' per month was 22.2 (13.1) in the MDE health state, 18.2 (14.3) in response, 14.9 (14.4) in remission, and 14.8 (15.1) in recovery. The working hours lost per month were calculated by consecutively converting calendar days to working days (multiplying by $61.77 \%$ ), accounting for 7.6 working hours per day and adjusting to the TRD population by multiplication with the average working time in the active TRD population of $85.34 \%$. Thereby, the reported absenteeism corresponds to an average number of working hours lost per month per health state of, respectively, 89 in MDE, 73 in response, 60 in remission, and 59 in recovery.

\subsection{Costs}

Direct costs for (day) hospitalization, visits, tests, and pharmacological and non-pharmacological treatments amounted to an average yearly cost of $€ 9012$ per TRD patient $(0.025-0.975$ percentile: $518-61,280)$. The average monthly direct cost per health state was $€ 1214.32$ in the MDE health state, $€ 157.65$ in response, $€ 129.23$ in remission, and $€ 93.93$ in recovery (Fig. 1). Hospitalization is an important driver in the total direct cost for TRD, with an average reported length of stay of 31.9 days in a general hospital and 68.0 days in a psychiatric hospital.
Subpopulation analysis showed numerically higher monthly MDE costs for relapse compared with baseline MDE ( $n=65, € 1223$ vs $€ 841$ ), and for the fourth or higher treatment line compared with the third treatment line ( $n=88, € 1833$ vs $€ 954)$, although not statistically significant.

Indirect costs due to absenteeism were based on the average number of working hours lost per month and a labor cost of $€ 39.70$ per working hour lost, applied to $81.5 \%$ of the active TRD patients. This corresponds to a monthly indirect cost of $€ 2878.05$ in MDE, $€ 2359.48$ in response, $€ 1931.66$ in remission, and $€ 1918.70$ in recovery. In the MDE health state, $70 \%$ of the total cost is indirect ( $€ 2878$ vs $€ 1214$ monthly cost, Fig. 2).

\section{Discussion}

This study provides the first report of real-world treatment patterns, outcomes, and resource utilization of TRD patients in specialized care in Belgium and the associated direct and indirect economic burden according to TRD-related health states. The patients in the study were included from different geographical regions and all different health care settings across Belgium, and the resulting baseline demographic characteristics align with other TRD studies; thereby, this study can be considered representative for the Belgian TRD patient population. The comorbidities at baseline were relatively high, which is in line with reported increased comorbidity levels in TRD compared with MDD [12].
Fig. 2 Monthly direct and indirect costs per health state. $M D E$ major depressive episode

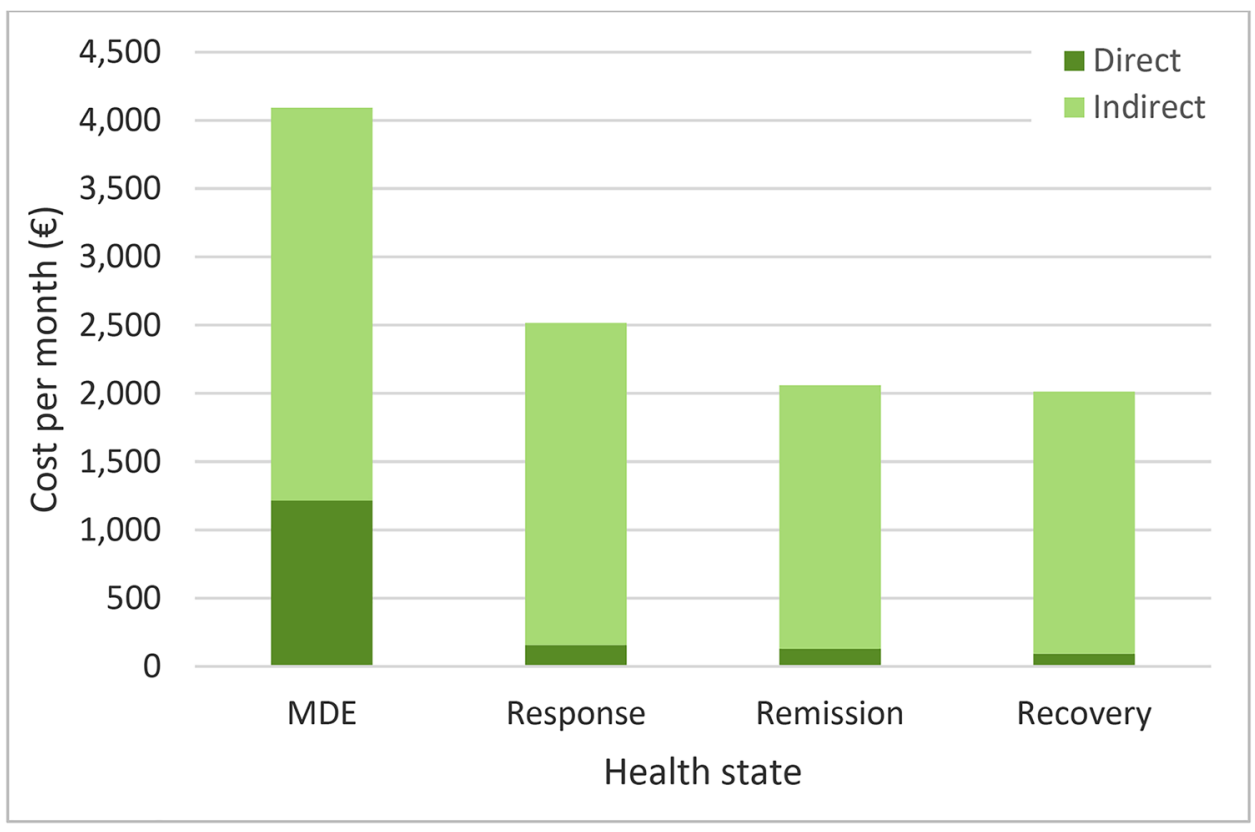

Abbreviation: $\mathrm{MDE}=$ major depressive episode 
As third-line treatment (first-line TRD), monotherapy and augmentation therapy were most commonly prescribed. Among patients who switched treatment, combination and/ or augmentation therapies further increased in fourth-line treatment, in line with clinical guidelines [22-24]. Twentyfour percent of patients did not reach response to any therapy during the study period and remained in the MDE health state, confirming the reported unmet need for a subgroup of MDD patients who do not adequately respond to available therapies [7, 23, 25].

Of the patients that did respond to therapy during the study period, $61.1 \%$ relapsed, in line with observational studies [8]. Only $28.0 \%$ of patients reached recovery, of whom nearly one third had a recurrence during the observation period. As a result, $80.8 \%$ of patients did not reach or maintain recovery at the end of the observation period. In addition, the number of recurrences might be underestimated, as the follow-up time was censored.

Based on the collected resource utilization, the average direct cost per year was quantified as $€ 9012$ per patient, which is 1.5 -fold higher than the average direct cost of an MDD patient [15]. This is in line with international studies reporting a 2-fold increase in costs for TRD compared with MDD [10, 13, 14]. The direct cost of TRD is mainly driven by hospitalization, observed for one third of the patients, for which the reported average length of stay is consistent with mental health reports [26].

Furthermore, the direct cost was strongly health-state dependent and hence related to treatment efficacy, with a monthly cost of $€ 1214$ for TRD patients who do not respond to treatment. These results are comparable to findings from a retrospective cohort study conducted in the UK [27] and international reports on quality of life and costs in function of disease severity and treatment efficacy $[9,10,28]$.

More than half of the patients were on sick leave or disability at baseline, of whom $<10 \%$ were able to restart working during the study period. This is aligned with international publications, reporting a substantially higher impact on professional functioning in TRD compared with MDD patients $[9,10,13]$. The indirect costs due to absenteeism correlate to $70 \%$ of the total MDE cost, comparable with the overall observed share of indirect costs in mental health of $68 \%$ as reported by the OECD [29].

The methodological limitations of the study are inherent to its observational nature and design. The method used is dependent on the quality of the record keeping. Given the patient numbers, the study was mainly descriptive and not sufficiently powered to conduct statistical comparison between groups. The exact number of excluded patients was not traced; as the main exclusion criterion was not fulfilling the TRD criterium and exclusion due to refusing participation or insufficient data was rather exceptional, the impact on the generalizability is considered limited. Treatment patterns were identified based on patients' medical records, which does not allow adherence and treatment duration follow-up and might underestimate the number of non-pharmacological therapy visits. The retrospective design did not allow us to adequately evaluate treatment response. The direct costs quantified in this study were based on psychiatrists' medical records, which might underestimate actual resource utilization and costs of non-mental health care, such as concurrent comorbidities and complications, which have been reported to account for up to $66-71 \%$ of the direct costs [30]. In addition, in the indirect cost calculation, only absenteeism was taken into account, while presenteeism and caregiver burden also have a substantial societal impact. Further research is warranted to investigate long-term management and outcomes.

\section{Conclusion}

This Belgian retrospective cohort study substantiates the remaining unmet need in current clinical practice in TRD and the associated economic burden, mainly in the MDE health state and driven by hospitalization and absenteeism. The results of the study underscore the need for effective treatment options for TRD patients, as medical resource utilization for patients who achieved treatment benefit (response, remission, and recovery) was strongly reduced.

Supplementary Information The online version contains supplementary material available at https://doi.org/10.1007/s41669-021-00306-2.

Acknowledgements The authors would like to thank Sofie Van Gestel, $\mathrm{PhD}$, for medical writing assistance and Linde Buntinx, $\mathrm{PhD}$ for data collection.

\section{Declarations}

Funding/support This research was supported by Janssen-Cilag NV, Beerse, Belgium.

Potential conflicts of interest De Vos C., Peeters E., Pype S. and Vandersmissen I. are employees of Janssen-Cilag NV. Realidad, employer of Strens D., received consulting fees from Janssen-Cilag NV. Dr Degraeve has served as speaker/member of an advisory board/has received research support from Janssen-Cilag NV, EG, Eli-Lilly, AstraZeneca, Sanofi, Pfizer, Otsuka, GSK, Lundbeck, and Pfizer. Dr Dreesen has received support from Janssen-Cilag NV and EG. Dr De Bruecker and Dr Kestens have received research support from Janssen-Cilag NV.

Ethics approval Ethics approval was provided by the GHdC (Grand Hôpital de Charleroi) on April 25, 2019 (reference G2-2019-E002). The study was conducted in accordance with all applicable laws in Belgium. Data management and analysis was conducted compliant to all legislation related to data protection, and additional ethics approval for sites where retrospective studies are validated by ethical committees.

Consent to participate For each patient included in this retrospective, non-interventional cohort study, the participating physician provided an 
anonymously filled in electronic case record form. Patient confidentiality was maintained at all times. All patients were informed about the study by the physician, who provided them with a patient information document. All living patients consented for participation.

Consent for publication All patients were informed about the study by the physician, who provided them with a patient information document.

Availability of data and material The analyzed data are included in this published article, the datasets generated and/or analyzed during the current study are available from the corresponding author on reasonable request.

\section{Code availability Not applicable.}

Authors' contributions Authors Vandersmissen and Strens designed the outline of the study, in collaboration with authors Degraeve, Peeters, Pype and De Vos. Authors Gillain, Degraeve, Dreesen, De Bruecker, Buntinx, Beke, Kestens, Valassopoulou, and Verhelst conducted study data collection. Author Strens conducted overall study data collection and statistical analysis. All authors contributed to and approved the final manuscript.

Open Access This article is licensed under a Creative Commons Attribution-NonCommercial 4.0 International License, which permits any non-commercial use, sharing, adaptation, distribution and reproduction in any medium or format, as long as you give appropriate credit to the original author(s) and the source, provide a link to the Creative Commons licence, and indicate if changes were made. The images or other third party material in this article are included in the article's Creative Commons licence, unless indicated otherwise in a credit line to the material. If material is not included in the article's Creative Commons licence and your intended use is not permitted by statutory regulation or exceeds the permitted use, you will need to obtain permission directly from the copyright holder. To view a copy of this licence, visit http://creativecommons.org/licenses/by-nc/4.0/.

\section{References}

1. WHO. Depression Fact Sheet; 2019. https://www.who.int/newsroom/fact-sheets/detail/depression. Accessed 7 Mar 2021.

2. WHO. Depression and Other Common Mental Disorders. Global Health Estimates; 2017. WHO-MSD-MER-2017.2-eng.pdf. Accessed 7 Mar 2021.

3. Al-Harbi KS. Treatment-resistant depression: therapeutic trends, challenges, and future directions. Patient Prefer Adherence. 2012;6:369.

4. Haesebaert F. Dépression résistante: vers une prise en considération des comorbidités et de la iatrogénie. Eur Psychiatry. 2014;29(8):663-4.

5. Olchanski N, McInnis Myers M, Halseth M, Cyr PL, Bockstedt L, Goss TF, Howland RH. The economic burden of treatmentresistant depression. Clin Ther. 2013;35(4):512-22.

6. Bauer M, Pfennig A, Severus E, Whybrow PC, Angst J, Möller HJ. World Federation of Societies of Biological Psychiatry (WFSBP) guidelines for biological treatment of unipolar depressive disorders, part 1: Update 2013 on the acute and continuation treatment of unipolar depressive disorders. World J Biol Psychiatry. 2013;14(5):334-85.

7. CHMP - Committee for Medicinal Products for Human Use. Guideline on clinical investigation of medicinal products in the treatment of depression. European Medicines Agency; 2013. https://www.ema.europa.eu/en/documents/scientific-guideline/ guideline-clinical-investigation-medicinal-products-treatmentdepression_en.pdf. Accessed 7 Mar 2021.

8. Rush AJ, Trivedi MH, Wisniewski SR, Nierenberg AA, Stewart JW, Warden D, Niederehe G, Thase ME, Lavori PW, Lebowitz BD, McGrath PJ, Rosenbaum JF, Sackeim HA, Kupfer DJ, Luther J, Fava M. Acute and longer-term outcomes in depressed outpatients requiring one or several treatment steps: A STAR $* D$ report. Am J Psychiatry. 2006;163:1905-17.

9. Johnston KM, Powell LC, Anderson IM, Szabo S, Cline S. The burden of treatment-resistant depression: A systematic review of the economic and quality of life literature. J Affect Disord. 2019;242:195-210.

10. Mrazek DA, Hornberger JC, Altar CA, Degtiar I. A review of the clinical, economic, and societal burden of treatment-resistant depression: 1996-2013. Psychiatry Serv. 2014;65:977-87.

11. Feldman RL, Dunner DL, Muller JS, Stone DA. Medicare patient experience with vagus nerve stimulation for treatment-resistant depression. J Med Econ. 2013;16(1):62-74.

12. Kubitz N, Mehra M, Potluri RC, Garg N, Cossrow N. Characterization of treatment resistant depression episodes in a cohort of patients from a US commercial claims database. PLoS ONE. 2013;8(10): e76882. https://doi.org/10.1371/journal.pone.00768 82.

13. Amos TB, Tandon N, Lefebvre P, Pilon D, Kamstra RL, Pivneva I, Greenberg PE. Direct and indirect cost burden and change of employment status in treatment-resistant depression: A matchedcohort study using a US commercial claims database. J Clin Psychiatry. 2018;79(2):17m11725.

14. Ivanova JI, Birnbaum HG, Kidolezi Y, Subramanian G, Khan SA, Stensland MD. Direct and indirect costs of employees with treatment-resistant and non-treatment-resistant major depressive disorder. Curr Med Res Opin. 2010;26(10):2475-84.

15. Karakaya G. Evolutie van de prevalentie en de kostprijs van chronische ziektes. Onafhankelijke Ziekenfondsen; 2015.

16. Karyotaki E, Smit Y, Cuijpers P, Debauche M, De Keyser T, Habraken H, Pitchot W, Raes F, Salomez D, Gillain B, Fairon N, Paulus D, Robays J, Holdt Henningsen K. The long-term efficacy of psychotherapy, alone or in combination with antidepressants, in the treatment of adult major depression. Good Clinical Practice (GCP) Brussels: Belgian Health Care Knowledge Centre (KCE); 2014. KCE Reports 230. D/2014/10.273/72. The longterm efficacy of psychotherapy, alone or in combination with antidepressants, in the treatment of adult major depression (fgov. be). Accessed 7 Mar 2021.

17. Dunlop BW, Gray J, Rapaport MH. Transdiagnostic clinical global impression scoring for routine clinical settings. Behav Sci. 2017;7(3):40. https://doi.org/10.3390/bs7030040.

18. Riedel M, Möller HJ, Obermeier M, Schennach-Wolff R, Bauer M, Adli M, Kronmüller K, Nickel T, Brieger P, Laux G, Bender W, Heuser I, Zeiler J, Gaebel W, Seemüller F. Response and remission criteria in major depression-a validation of current practice. J Psychiatr Res. 2010;44(15):1063-8.

19. Greenwood M. A report on the natural duration of cancer. In: Reports on public health and medical subjects, vol. 33. London: His Majesty's Stationery Office; 1926. pp. 1-26.

20. INAMI listings. Nomenclature: https://ondpanon.riziv.fgov.be/ Nomen/nl/search consulted May 2019. Medication: https://ondpa non.riziv.fgov.be/SSPWebApplicationPublic/nl/Public/ProductSea rch consulted May 2019.

21. Eurostat. Labor costs in the EU. https://ec.europa.eu/eurostat/ documents/2995521/9720156/3-11042019-BP-EN/3240675b5513-41a4-8b28-3f5e24c55b70. Accessed 7 Mar 2021.

22. APA. American Psychiatric Association: Practice Guideline For The Treatment of Patients With Major Depressive Disorder; 2010. 
3rd Edition. https://psychiatryonline.org/pb/assets/raw/sitewide/ practice_guidelines/guidelines/mdd.pdf Accessed 7 Mar 2021.

23. N.I.C.E, National Institute for Health and Clinical Excellence: Guidance, in Depression: The Treatment and Management of Depression in Adults (Updated Edition). Leicester (UK): British Psychological Society; 2010.

24. Declercq T, Habraken H, Van Den Ameele H, Callens J, De Lepeleire J, Cloetens H. Richtlijn Voor Goede Medische Praktijkvoering: Depressie bij volwassenen. Antwerpen: Domus Medica vzw; 2017. Richtlijn depressie bij volwassenen_0.pdf (domusmedica. be). Accessed 7 Mar 2021.

25. Vrieze E. Ketamine: breakthrough as "anti-antidepressivum"? Tijdschr Psychiatr. 2018;60(2):74-6.

26. Umbach I, Vanrillaer V. Verblijven in een psychiatrische omgeving. Onafhankelijke Ziekenfondsen; 2014.

27. Denee T, Ming T, Waller J, Bailey T, Rajkovic-Hooley O, Middleton-Dalby C, Le HH, Zhang Q, McCrone P, Taylor D. A retrospective chart review study to quantify the monthly medical resource use and costs of treating patients with treatment resistant depression in the United Kingdom. Curr Med Res Opin. 2020. https://doi.org/10.1080/03007995.2020.1857580.

28. Sobocki P, Ekman M, Agren H, Krakau I, Runeson B, Mårtensson B, Jönsson B. Health-related quality of life measured with EQ-5D in patients treated for depression in primary care. Value Health. 2007;10(2):153-60. https://doi.org/10.1111/j.1524-4733.2006. 00162.x.

29. OECD. Health at a glance: Europe 2018. Factsheet on promoting mental health; 2018. http://www.oecd.org/health/health-syste ms/OECD-Factsheet-Mental-Health-Health-at-a-Glance-Europe2018.pdf. Accessed 7 Mar 2021.

30. Simon GE, VonKorff M, Heiligenstein JH, Revicki DA, Grothaus L, Katon W, Wagner EH. Initial antidepressant choice in primary care. Effectiveness and cost of fluoxetine vs tricyclic antidepressants. JAMA. 1996;275(24):1897-902.

\section{Authors and Affiliations}

\section{B. Gillain ${ }^{1}$. G. Degraeve $e^{2,3,4} \cdot$ T. Dreesen ${ }^{5}$. G. De Bruecker ${ }^{6} \cdot$ E. Buntinx ${ }^{7} \cdot$ D. Beke ${ }^{8} \cdot$ C. Kestens $^{9} \cdot$ E. Valassopoulou ${ }^{10}$. F. Verhelst ${ }^{11} \cdot$ E. Peeters ${ }^{12} \cdot$ S. Pype ${ }^{12} \cdot$ C. De Vos $^{13} \cdot$ D. Strens ${ }^{14} \cdot$ I. Vandersmissen $^{13}$}

1 Clinique Saint Pierre, Ottignies, Belgium

2 Psychiatric Center Guislain, Ghent, Belgium

3 Private Practice, Maldegem, Belgium

4 AZ Alma, Eeklo, Belgium

5 Mentona Centre for Psychiatry and Psychotherapy, Bilzen, Belgium

6 Psychiatric Center Ariadne, Lede, Belgium

7 Medical Center Anima, Alken, Belgium

8 Psychiatric Center Menen, Menen, Belgium
Centre Hospitalier Régional de Huy, Huy, Belgium

10 Centre Hospitalier Régional de la Citadelle, Liège, Belgium

11 Grand Hôpital de Charleroi, Charleroi, Belgium

12 Department Medical Affairs, Janssen-Cilag NV, Beerse, Belgium

13 Department Market Access, Janssen-Cilag NV, Antwerpseweg 15-17, 2340 Beerse, Belgium

14 Realidad bvba, Grimbergen, Belgium 